\title{
A Unique Sequence Of Financial Accounting Courses Featuring Team Teaching, Linked Courses, Challenging Assignments, And Instruments For Evaluation And Assessment
}

Heidemarie Lundblad, (Email: heidemarie.lundblad@csun.edu), California State University, Northridge Barbara A Wilson, (Email: barbara.wilson@csun.edu), California State University, Northridge

\begin{abstract}
The Department of Accounting at California State University Northridge (CSUN) has developed a unique sequence of courses designed to ensure that accounting students are trained not only in technical accounting, but also acquire critical thinking, research and communication skills. The courses have proven effective and have embedded assessment measures that are used to evaluate and document student progress. The assessment measures also provide feedback to faculty and have led to numerous improvements over time. The Intermediate Accounting Sequence begins with a one (semester) unit bridge course that reviews the lower-division accounting material, introduces intermediate accounting concepts, and provides a base measure of students' communication skills through a writing assignment. The next three-unit intermediate accounting course (ACCT351) is linked with a two-unit accounting communication course (351COM). These linked courses share unstructured case assignments written by the accounting faculty that require students to identify the accounting issue(s), research the authoritative literature in GAAP, and write a professional one-page document for each case that demonstrates critical thinking and appropriate documentation. The structure of the linked courses is based on team work, and has the indirect benefit of promoting collegiality among faculty and fostering a culture of critical thinking throughout the accounting program. The skills acquired in 351/351COM are reinforced in subsequent courses through the use of similar assignments and evaluation and assessment
\end{abstract}

\section{INTRODUCTION}

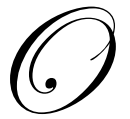

nce upon a time, it was sufficient for accounting graduates to be able to remember and apply a rather limited number of accounting rules. Today, employers expect graduates not only to be proficient "number crunchers," but also to have good communication, research, and critical thinking skills. Accounting educators face a daunting challenge: How can we ensure that students are properly trained in the ever expanding body of accounting standards, while at the same time expand into additional areas to develop the communication, research, and critical thinking skills that are so highly prized by employers? Furthermore, how can we expect to do this within the confines of the traditional curriculum and in the face of limited resources? Even if instructors are willing to venture into these areas, they may feel that they lack the skills and/or the time to teach and evaluate these abilities.

One traditional solution has been to require students to enrol in an additional English class, in the hope that this would provide sufficient training in communication skills. Training in critical thinking skills may be considered the province of the Philosophy department, while, time permitting, the business reference librarian might be asked to provide a one hour workshop on researching academic databases such as ABI/INFORM, LexisNexis, and Mergent 
Online. This type of "outsourcing" relieves the workload of the accounting instructor and may in some cases lead to some improvement in the students' skills. However, in many cases, this improvement is illusionary. For example, despite the best intentions of English department instructors, accounting students show scant improvement in a business writing style after completing a required liberal arts writing course. One reason seems to be the belief among students that communication and research skills are not really important for the accounting profession. In fact, many students with poor communication skills self-select into accounting because they do not realize the importance of communication in today's accounting environment.

To summarize the problem:

1. Accounting graduates must be proficient in technical accounting skills, but must also be good communicators, researchers, and critical thinkers

2. Accounting instructors have limited time and or training to teach these skills within the traditional accounting curriculum

3. Accounting students consider skills courses (e.g., an English class) to be unnecessary burdens required for some unfathomable reason by the University.

Our program addresses these issues and provides an innovative solution that has been successful and is readily adaptable to other programs. The program has a number of significant pedagogical advantages:

1. Intermediate accounting course (ACCT 351) linked with a communication course (351COM)

2. Joint assignments and shared grading (ACCT 351 and 351COM)

3. $\quad$ Sequenced assignments

4. Tight focus on a limited number of important objectives

5. Several short assignments and rapid feedback

6. $\quad$ Embedded assessment instrument

CSUN is a large, urban, ethnically diverse campus. Many students are learning English as a second language. Over half of our students take the lower-division accounting courses at a community college, and most are employed. Consequently, there is frequently a significant interval between the time our students take lower division and intermediate accounting. Our program is designed to take these factors into consideration.

\section{THE INTERMEDIATE ACCOUNTING SEQUENCE AT CSUN}

1. Accounting 350 (ACCT 350) - The Bridge Course (1 semester unit)

2. Accounting 351 (ACCT 351) - Intermediate Accounting I (3 semester units)

3. Accounting 351Com (351COM) - Linked Communication Course (2 semester units)

4. Accounting 352 (ACCT 352) - Intermediate Accounting II (3 semester units)

\section{Accounting 350 — The Bridge Course}

Students must meet certain grade point requirements in their lower-division accounting courses to be admitted to the accounting program. Nevertheless, for a variety of reasons, many students need to refresh or relearn basic accounting topics. Consequently, before students are permitted to enrol in ACCT 351, they must complete the bridge course (ACCT 350). In this one-unit course, students review the accounting equation, the basic financial statements, and present value techniques. We also evaluate students' communication skills in this course.

Experience has taught us that through grade inflation, some students with inadequate English skills may receive high grades in liberal arts courses, even though they lack satisfactory oral and written skills. We believe that such a student has little if any chance to successfully complete the accounting program. Consequently, students are required to write a one-page letter to a client (the "Amelia letter") on an accounting subject (see Appendix A for the writing prompt). This letter is evaluated for basic English skills by members of the ACCT 351/351COM team. The papers are not actually graded at this time; instead, students with extremely poor English skills are identified and 
referred to the ACCT 350 instructor who meets with and counsels each of these students. ${ }^{1}$ We cannot prevent students who demonstrate extremely limited English skills in the "Amelia letter" from enrolling in ACCT 351. However, students are advised to complete a (specified) English course prior to enrolling in Intermediate Accounting. Students must also sign a document that contains the same information. A copy of this document is given to the ACCT 351 and 351COM instructors. If a student, despite the advice received, insists on enrolling in ACCT 351 and $351 \mathrm{COM}$, the $351 / 351 \mathrm{COM}$ team again warns the student that $\mathrm{s} / \mathrm{he}$ may not have sufficient language skills to succeed in $351 \mathrm{COM} .{ }^{2}$

\section{Accounting 351 And Accounting 351COM—Linked Courses}

At first glance ACCT 351 is a standard first Intermediate Accounting course, but several key elements distinguish ACCT 351 from a standard accounting course.

1. Most significantly, it is tightly integrated with $351 \mathrm{COM}$, the accounting communication course. Students must enrol in both courses at the same time.

2. Students must complete a series of linked research assignments that are discussed and graded in both ACCT 351 and 351COM. These assignments are discussed in more detail in the next section.

3. The instructors for ACCT 350, ACCT 351 and 351COM work as a team. Prior to the semester, they begin coordinating the course schedules to ensure a smooth sequence of assignments. Furthermore, the team meets approximately every two weeks throughout the semester to discuss assignments and complete a norming process for grading--and any other issues that may arise.

The following sections discuss in more detail the Accounting Communication course (351COM), followed by a description of assignments, the team approach, how we operationalize the use of shared cases, and how the model is continued in subsequent courses. ACCT 352 will not be covered in this paper.

\section{ACCOUNTING 351COM}

This is a two-unit communication course taught by business communication professors. Because 351COM is a required accounting course, the written assignments are accounting specific. Emphasis is on an effectively written document that is technically correct. Most importantly, 351COM reinforces the message we are sending to our accounting majors: Communication skills are critical for success in an accounting career.

The 351COM class focuses on a business style of writing for the accounting profession. Emphasis is placed on direct organization (purpose up front and strong topic sentences); proper documentation of the authoritative accounting literature; logical flow; ability to interpret and paraphrase accounting standards; a clear and concise writing style; the ability to distinguish between facts, conclusions, and recommendations; and being able to communicate with a variety of audiences.

In 351COM instructors also teach and evaluate formal oral presentation skills. Throughout the semester, each case is formally presented by at least one group of students in the communication course.

\section{Assignments And The Student Model}

To teach technical accounting as well as the communication, research, and critical thinking skills, the faculty has designed a series of assignments that requires the ability to evaluate a situation, identify the accounting issue, research the issue, identify possible solutions, select and support a solution, and then communicate the information in a professional manner. To provide optimum writing opportunities, students complete several short assignments that are designed to improve their writing skills, rather than one large end-of-term paper that may be

\footnotetext{
${ }^{1}$ These letters are eventually graded by the 351COM instructors and form the basis of the first assignment in 351COM. This subject is further discussed in the section on 351COM.

${ }^{2}$ Students must maintain at least a "C" in all accounting courses to continue in the program. Additionally, they may only repeat a limited number of courses.
} 
festooned with valuable comments by the instructor and roundly ignored by the student. The five assignments are spaced throughout the semester on a two-week cycle and increase in the level of difficulty.

Assignment 1: Revision of "Amelia letter"

As discussed above, students write a letter to a client in ACCT 350. This letter is graded and returned the first day of class in 351COM. Students are required to revise according to written comments by the instructor and resubmit the revised letter for a grade in $351 \mathrm{COM}$.

\section{Assignment 2: Research Questions}

Each semester the ACCT 351 instructors select five accounting questions. Students must find the appropriate accounting standard that applies to the event or transaction. We try to include some relatively easy questions and some that go beyond the material covered in the course text book (see Appendix B for a set of sample questions).

Since the body of accounting rules has become very large, complex, and is frequently modified, it is unreasonable to expect that accounting students can memorize all of it by the time they graduate. Instead, students must learn to research the accounting standards. We require students to purchase the Financial Accounting Research System (FARS) on CD-ROM. ${ }^{3}$ In $351 \mathrm{COM}$, students are introduced to the databases and to research techniques using Boolean operators, wildcards, and proximity symbols.

Students have three weeks to research the questions. During that time they review the proper citation and referencing rules in 351COM. Finally, they prepare a concise, properly referenced one-page document written to a manager in which they communicate the answers to the research questions.

Students submit one copy to the ACCT 351 instructor and one copy to the 351COM instructor. The ACCT 351 instructor grades for technical content and then gives the graded copy to the $351 \mathrm{COM}$ instructor. The $351 \mathrm{COM}$ instructors grade their copy for writing skills and incorporate the accounting content grade into the writing grade. A paper that is technically incorrect will not receive a very good communication grade - a document must be technically correct to be effectively written. Both graded copies are returned to the students by the 351COM instructor. The grading method described in this section is followed for all subsequent assignments.

At the end of the semester, students revise all written documents and resubmit their work in a portfolio. This gives students an opportunity to respond to the written comments by both the accounting and communication instructors. The overall improvement demonstrated in the students' portfolio counts ten percent towards their final $351 \mathrm{COM}$ grade.

\section{Assignments $3-5$}

The next three assignments are research cases that build on the students' research and documentation skills and introduce critical thinking skills. The ACCT351 instructors write and/or select cases based on the following criteria:

1. Cases must be fairly short for two reasons:

a. Time constraints. Students have only two weeks between due dates. Therefore, instructors have a one-week turnaround time for grading before the next case is presented.

b. Space constraints for papers. The body of the completed paper cannot exceed one page (references are on page two). If appropriate, an attachment may be included on a second page.

\footnotetext{
${ }^{3}$ We have experimented with the online version but find the current version inferior to the CD-ROM.
} 
2. Cases must be reasonably unstructured to give students the opportunity to practice critical thinking. In an unstructured case (opposed to a disguised word problem) students analyze a situation and identify the accounting issue(s) instead of merely looking up the correct answer in the text book. The accounting issue must be substantive and go beyond what students have already learned (see Appendix C for the sample Softbank case).

3. Cases must contain one or two significant accounting issues that require research beyond what students have already learned, but fit into the technical topics covered in Intermediate Accounting I.

Cases are posted for downloading on the instructors' web pages at the beginning of the semester to give students ample time to properly research each case and prepare quality papers based on the detailed instructions provided in 351COM. Unfortunately, some students tend to wait until the last minute. This leads to disappointment and frustration for students and instructors. To reduce (if not eliminate) procrastination, we have developed a series of required steps:

1. Students research the case and write a one-page draft. In the 351COM class, students are assigned to a group. For each case, two groups per 351COM section are selected to give an oral presentation. Another group is designated the Challenge Team. It must critically evaluate the content of the presentation and give constructive feedback to the presenters. At the end of this class, every student exchanges his/her draft and completes a peer review using an evaluation sheet prepared by the communication instructor.

2. On the same day, a short quiz is given in ACCT 351 based on the technical facts of the case. At this time instructors do not give "answers," they merely facilitate student discussion of the case.

3. A final, revised paper is prepared on the basis of feedback from peer reviews, challenge team critique, class discussion, and the quiz. It is submitted one week later in both ACCT 351 and 351COM.

Figure 1: Student Model for Case Assignments-A Two-Week Cycle

3. Students turn in polished paper in both classes. Begin next case.

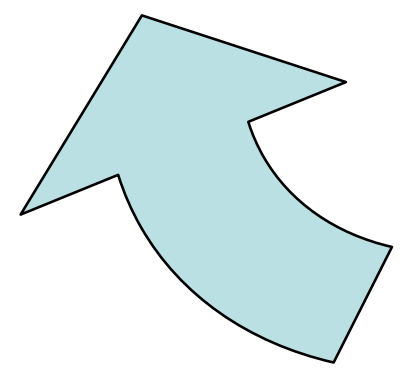

2. Selected groups present the case and everyone does a peer review in 351COM. Quiz in 351. 351

Quiz on accounting material
1. Students discuss the case, research the appropriate literature, and write a draft.

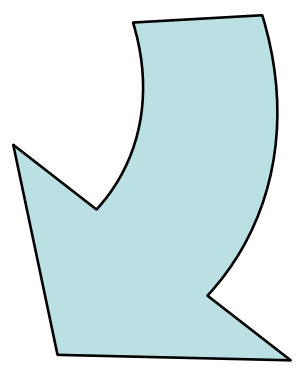


The quiz, draft paper, peer review, and oral presentation one week prior to the due date, teaches students the value of reviewing and revising a paper. All too many of our students believe that editing a paper means fixing the commas. By establishing a process that encourages and rewards revision, we hope to inculcate behaviour patterns that will be beneficial in the students' future professional career as well as in other course assignments.

\section{THE ROLE OF THE FACULTY}

To ensure a successful program, the accounting and communication faculty must work as a team. The accounting faculty select the cases, teach, and grade the technical accounting skills, while the communication faculty are responsible for teaching and grading communication and research skills.

A critical component in the process is that the accounting faculty present each case to the communication faculty, identifying the accounting issues and the authoritative accounting literature and explaining the solution. Communication relies on writing skills, but an effective document must also contain correct technical content. Since the communication instructors are not trained accountants, they must receive careful instruction from the accounting instructors. This presentation takes place in the team meetings. In addition, the accounting instructors consult with each other and prepare a detailed grading rubric for the technical material (see Appendix D for the Softbank Grading Rubric).

The grading rubric serves four purposes: It (1) helps the communication instructors to understand the accounting issues and to quickly see whether a paper has properly identified and researched the accounting issues in the case; (2) helps to ensure that papers are graded fairly, consistently, and comparably by different accounting instructors; (3) makes it possible to use student assistants to help with grading; and (4) serves as an embedded course measure to assess student outcomes.

Once the accounting faculty have discussed the case and the customized grading rubric with the communication faculty, the lead communication instructor prepares a written prompt for the students in 351COM. Information for audience analysis is provided as well as a context for a written document - either a memo to a manager or a letter to a client. Students are given information to help define the scope of the accounting issues and suggestions for researching GAAP. It should be emphasized, however, that we do not give the students answers. In addition to preparing a writing prompt, the lead communication instructor also prepares a peer review sheet highlighting writing qualities that should be critiqued by the students in the peer review process. But perhaps most importantly, 351COM instructors practice holistic grading: They incorporate the technical accounting grade into the writing grade for each paper, as well as into the grade for the oral presentation.

A generic evaluation matrix for critical thinking is reviewed with the students and they submit a copy of it with each paper in ACCT 351 (see Appendix E). The matrix describes the criterion for determining the relevant facts, identifying the accounting issue, researching the authoritative literature, and interpreting and applying the accounting literature to the issues. Graders used the generic evaluation matrix to enter points in the appropriate sections. Since the 351COM faculty member receives the graded paper with the attached matrix, s/he can quickly see how well a student performed on each section. (ACCT 351 instructors use this generic evaluation matrix to customize a grading rubric for each case.)

As can be seen from the discussion and the diagram below, the success of the program depends on preparation and cooperation amongst the team members. Careful planning and team work make it possible to deliver a quality program that is not burdensome to the faculty members involved. 
Figure 2: Faculty Model for Preparing and Grading Case Assignments
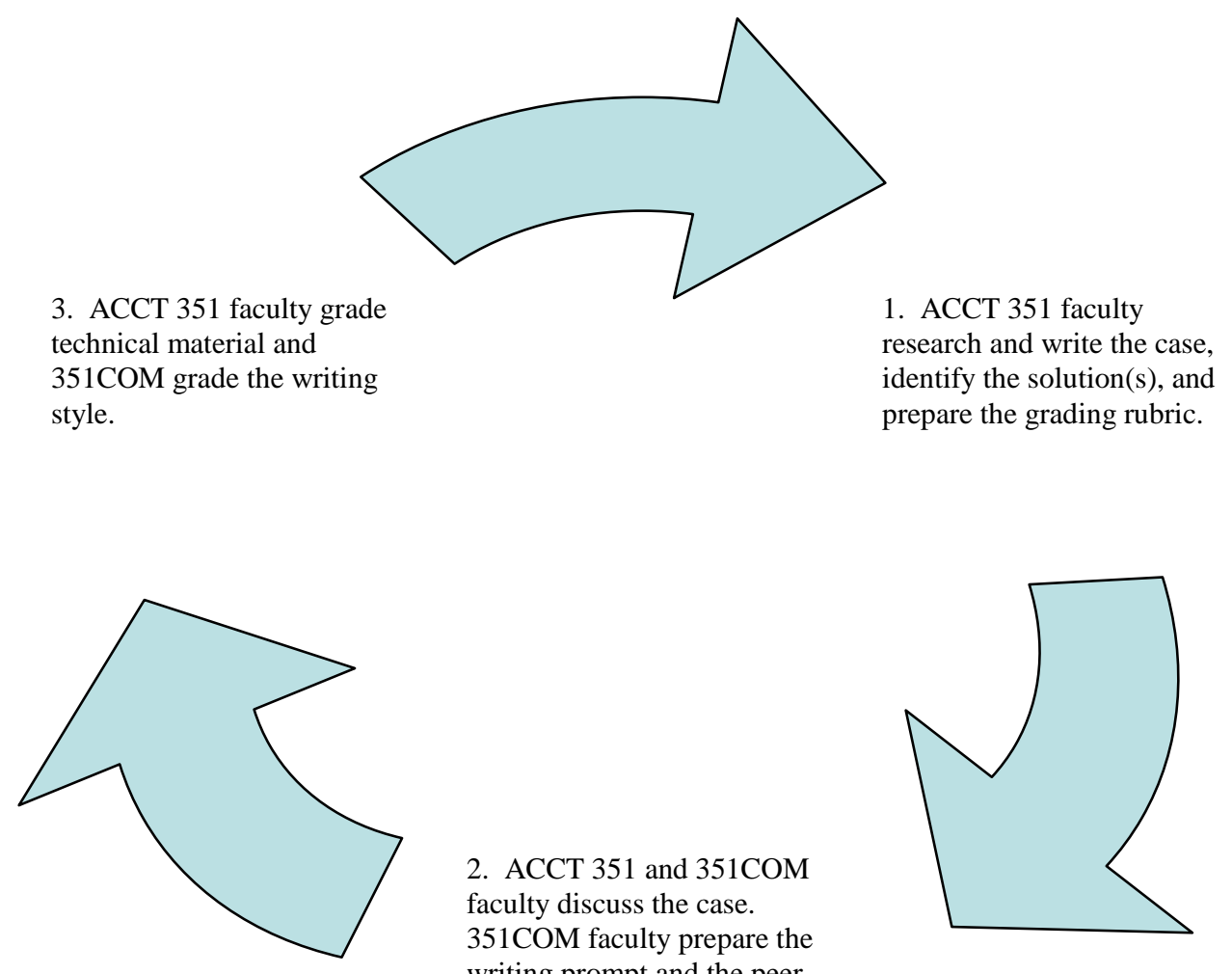

2. ACCT 351 and $351 \mathrm{COM}$

faculty discuss the case.

351COM faculty prepare the

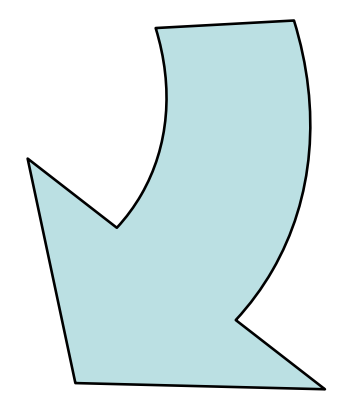
writing prompt and the peer review guide.

It takes some time to prepare a customized grading rubric, but it has significant benefits. First, by presenting the case and the customized grading rubric to the communication faculty, the accounting faculty can focus on grading the technical issues and have confidence that a paper with incorrect content from an accounting perspective will not receive a perfect grade for communication, regardless of how well it may be written. Incorrect information elegantly presented still results in a useless document!

Second, the customized grading rubric is also useful if there are multiple graders. We have been very successful in using student assistants (TAs) to help with grading. The accounting faculty meet with the TAs and complete a norming process with TAs to ensure consistency.

Finally, at the end of the semester we use the completed critical evaluation matrixes for assessment purposes. As shown in Appendix E, the matrix at the top has two columns: acceptable and unacceptable. Before grading, the accounting instructors determine the cutoff point that separates the two categories. A random sample of completed papers for one of the cases is selected. For this purpose, we make a slight adjustment to the matrix-Instead of assigning points for each category, we use check marks to indicate whether a paper is acceptable or unacceptable in each category.

\section{FOCUS ON CONTINUOUS IMPROVEMENT}

A major advantage of the model presented above is the ability to evaluate the degree of continuous improvement in research, critical thinking and communication skills throughout the accounting program. Subsequent courses, such as ACCT 352, use an appropriately adapted evaluation matrix to grade cases too. 
Although ACCT 352 does not have the benefit of a linked communication course, students must complete two or three cases that meet the same criteria as the cases selected for ACCT 351/351COM. Just as in 351/351COM, students attach the generic evaluation matrix to their papers. Papers are graded based on a detailed, annotated evaluation matrix.

In summary, this unique sequence of financial accounting courses has several advantages.

1. It can be adapted to other programs. Critical thinking, research, and communication skills are generic skills that can be integrated into any of the disciplines.

2. Multiple unstructured cases reinforce the critical thinking, research, and communication skills taught (learned). And, these skills can be reinforced in later courses--skills not used are quickly lost.

3. Students receive the message that they need to be proficient in more than just technical accounting skills.

4. The generic evaluation matrix communicates to students how they will be graded. Also, they know that succeeding courses will use a similar evaluation matrix.

5. The generic evaluation matrix provides an effective and efficient embedded assessment instrument. Since the measurement instrument is comparable, we can determine whether skills are improving across the curriculum and/or which areas need improvement. Continuous program improvements depend on meaningful assessment.

6. The customized grading rubric and generic evaluation matrix makes it possible to use student graders to grade increasingly technically complex papers.

7. The willingness of participating instructors to work as a team creates a culture that supports an integrated curriculum of knowledge, skills, and abilities. This is essential for the linked courses model, but it is also important for stand alone courses (such as our ACCT 352 course). By agreeing on course content and the cases, instructors can be reasonably assured that each of us reinforces the critical thinking, research, and communication skills.

\section{APPENDIX A}

\section{Pre-Writing Course-Based Assessment ${ }^{4}$}

\section{Facts}

A client of yours, Mrs. Amelia Emerson, is considering the purchase of corporate bonds being issued by the Butterscotch, Inc. As Mrs. Emerson's accountant, she seeks your advice about whether to make this investment. The bonds are 5-year debentures, which guarantee a 30 percent rate of return. Butterscotch, Inc. manufactures crystal figurines and music boxes.

Mrs. Emerson has provided you with a copy of Butterscotch's most recent unaudited financial statements (income statement and balance sheet), which are dated one year ago. Sally Butterscotch, who is the co-owner and wife of Billy Bob Butterscotch, prepared these statements. The company's debt-to-equity ratio is .20 and the income statement reports net income of $\$ 1,320,150$.

The financial statements do not provide any information about prior years. Nor do the financial statements contain notes disclosing significant accounting policies (accounting principles and methods used--inventory pricing, depreciation methods, etc.) or any other information such as the existence of loan agreement restrictions, dependency on a single customer or supplier, or contingencies, if any of these existed.

\section{Required}

Write a business letter advising Mrs. Emerson about her making an investment decision based on these financial statements. Be sure to discuss the financial statements in terms of reliance and reliability, including the ingredients of these primary qualities (and any other qualitative characteristics you deem appropriate). Very little

\footnotetext{
${ }^{4}$ Adapted from Kieso, D., Weygandt, J., and Warfield, T. (2001). Intermediate Accounting. New York: John Wiley \& Sons, Inc., $10^{\text {th }}$ edition, C2-11, p. 64
} 
credit will be given for merely quoting definitions or repeating verbatim the information provided in the facts. Mrs. Emerson is not a sophisticated businessperson and, therefore, you need to communicate in terms that she will easily understand.

\section{APPENDIX B}

\section{Accounting 351/COM Research Questions, Fall 2006}

1. Under what conditions can an internet company recognize revenue from an advertising barter transaction?

2. How should a company recognize the cash received in a sale of goods, if it also agrees to repurchase the goods at a future time?

3. How should companies that experienced a catastrophic loss as a result of the extraordinary events that happened on 9/11/2001, have accounted for such a loss?

4. If a company has made a firm, legally enforceable commitment to purchase goods in the following year at a fixed price and at then end of the current period it discovers that the market price for the goods have fallen, how, if at all, should this event be recognized?

5. Should an oil company accrue an environmental clean-up liability in anticipation of a possible future catastrophic accidental oil spill?

\section{APPENDIX C}

\section{Sample Case: Softbank -Accounting Artistry In Motion ${ }^{5}$}

(Prepared by Dr. Heidemarie Lundblad for Accounting 351/351COM, Fall 2006)

Softbank, a Japanese telecommunication company, just reported an amazing increase in the operating-profit margin on its mobile-phone unit from a wimpy $3.2 \%$ to an impressive $11.7 \%$ in just two months. How did Softbank manage this, without a commensurate increase in revenue? And why did the company's share price decline, despite such a dramatic increase in operating profitability?

\section{This Is What Happened}

Earlier in the year Tokyo based Softbank acquired assets from Vodafone Group PLC of the United Kingdom for about $\$ 15$ billion and now gets half of its revenue from Vodafone's mobile-phone operations. As a result of the added business Softbank reported a $\$ 12$ million profit for the quarter ended June 30, compared with a loss of $\$ 97$ million for the same period one year before. Vodafone probably sold its mobile unit because it had been losing customers and revenue. This trend has continued since Softbank took over operations on April 28, 2006. Average revenue per user -- a benchmark statistic in the mobile-phone industry that indicates how much money a company gets from each subscriber has continued to decline. Perhaps not surprisingly, Softbank's share price has also declined by $27 \%$ since the acquisition was made. Softbank paid $\$ 15$ billion for the mobile unit, including fixed assets -- network, transmission towers and other infrastructure - valued at a little more than $\$ 9$ billion. However, in Softbank's August 8, 2006 financial statement, the assets are shown at about half that amount. What did Softbank do with the $\$ 4.5$ billion? It increased the amount of goodwill reported on its balance sheet by an equal amount. According to Morse (2006) a company spokesman claimed that the assets were revalued properly and based on the advice of company auditors. Its published financial statements provided little explanation about this change.

In Japan fixed assets are depreciated over ten years, intangibles (including goodwill) over twenty years. Softbank is a Japanese company and reports under Japanese accounting rules.

\footnotetext{
${ }^{5}$ This case is based on publicly available information. For further information see: A. Morse and Y. Iwatani Kane: Outside Audit Softbank's Accounting Shift Raises Eyebrows. The Wall Street Journal, August 28, 2006; Page C1
} 


\section{Required}

1. Evaluate the company's actions under US GAAP and disclosure rules and explain the effect of its actions on reported financial performance.

2. Is a problem with the company's action under US GAAP?

3. Are there any ethical issues that might concern you?

\section{APPENDIX D}

\section{Sample Evaluation Matrix - SOFTBANK ${ }^{6}$}

\begin{tabular}{|c|c|}
\hline Case: SOFTBANK- 35 points - Excerpts attached & points \\
\hline \multicolumn{2}{|l|}{ Determine and State the Relevant Facts } \\
\hline 1. Operating profit margin increased from $3.2 \%$ to $11.7 \%$; revenue stayed same; Share price declined & 2 \\
\hline $\begin{array}{l}\text { 2. Reduced fixed assets from } \$ 9 \text { billion in April to about } \$ 4.5 \text { billion in August, increased goodwill on company } \\
\text { books by a like amount. }\end{array}$ & 2 \\
\hline 3. In Japan fixed assets depreciated over 10 years, goodwill over 20 years. & 2 \\
\hline \multicolumn{2}{|l|}{ Identify and State the problem } \\
\hline $\begin{array}{l}\text { Ethical issue: Who are the stakeholders? Is management misleading them by revaluing reported asset values } \\
\text { without providing sufficient disclosure? }\end{array}$ & 2 \\
\hline \multicolumn{2}{|l|}{ Identify and State the Accounting Issue(s) } \\
\hline 1. Possible asset impairment & 1 \\
\hline Accounting for goodwill & 1 \\
\hline reclassification of cost from fixed assets to goodwill & 1 \\
\hline 4. Depreciation of fixed assets; Goodwill amortization & 1 \\
\hline \multicolumn{2}{|l|}{ Research the Authoritative Literature - US GAAP } \\
\hline Revaluation of assets Change in estimate or error correction? FAS 154 (APB 20 par 10) & 2 \\
\hline Goodwill FAS142, Par. 18 -35 no amortization - impairment test & 2 \\
\hline Asset impairment: FAS144, Par. 7,-9; & 2 \\
\hline $\begin{array}{l}\text { Disclosure: Change in estimate: FAS 154, par 19-22; asset impairment: FAS144, Par. } 25,26 \text {; Accounting } \\
\text { policies: APB 22, par 6,8,12-15; SEC Reg. FD }\end{array}$ & 2 \\
\hline \multicolumn{2}{|l|}{$\begin{array}{l}\text { Interpret and Apply the Appropriate Accounting Literature to the Issue(s) } \\
\text { Support Solution: Discussion supports either US or Japanese position using reasons based on logical interpretation } \\
\text { of the relevant literature. }\end{array}$} \\
\hline \multirow{4}{*}{$\begin{array}{l}\text { US GAAP: The write down of fixed assets appears justified under FAS } 144 \text { - Asset Impairment - definition; Par. 7: } \\
\text { "...carrying amount of a long-lived asset (asset group) exceeds its fair value." } \\
\text { Goodwill may not be written up or amortized (FAS 142, par 18.); must be examined at least annually for potential } \\
\text { impairment (par 26). Impairment: Determination based on evidence of fair market value of the entity, such as: } \\
\text { "Quoted market prices in active markets are the best evidence of fair value ... if available." (FAS 142, par. 23). } \\
\text { This means stock price! There is no justification for increasing the value of goodwill. Softbank acquired assets, not } \\
\text { a company. No merger, hence NO goodwill! Existing goodwill should perhaps have been written down, not up. } \\
\text { Disclosure is required for revaluation (Change in estimate) (FAS 154/APB 20, par 33), also for write down of fixed } \\
\text { assets (income statement. FAS 144, par 25,26) }\end{array}$} & 3 \\
\hline & $\begin{array}{l}3 \\
2\end{array}$ \\
\hline & \\
\hline & 2 \\
\hline \multicolumn{2}{|l|}{ B. Ethical issues: } \\
\hline 1. Stakeholders: & \\
\hline a. Stockholders (not so important in Japan) & 1 \\
\hline $\begin{array}{l}\text { b. Creditors (primary interest group in Japan) } \\
\text { c. Management }\end{array}$ & \\
\hline $\begin{array}{l}\text { 2. Softbank's action is (is not) in the best interest of stake- holders. It is (is not) designed to mislead } \\
\text { investors or other stakeholders }\end{array}$ & 4 \\
\hline
\end{tabular}

\footnotetext{
${ }^{6}$ The actual matrix includes about six pages of appropriate excerpts from the authoritative literature.
} 


\section{APPENDIX E}

\section{Generic Critical Thinking Evaluation Matrix}

\begin{tabular}{|l|l|l|}
\hline $\begin{array}{l}\text { Case /Name } \\
: \text { Factor }\end{array}$ & $\begin{array}{l}\text { Irrelevant/ } \\
\text { Unacceptable }\end{array}$ & Acceptable \\
\hline Determine and state the relevant facts & & \\
\hline Identify and state accounting issues & & \\
\hline Research the relevant authoritative literature & & \\
\hline $\begin{array}{l}\text { Interpret and Apply the Accounting Literature to the Issue(s). } \\
\text { 1. Identify Solution(s) (alternative solutions may be possible) }\end{array}$ & \\
2. Select and Support A Solution: Discussion supports the selected solution using & \\
$\quad \begin{array}{l}\text { reasons based on logical interpretation of the relevant literature. } \\
\text { If appropriate supply references, schedules, journal entries }\end{array}$ & \\
\hline
\end{tabular}

1) Determine and State Relevant Facts: (Critical Thinking-reason)

a) Student sorts relevant material from irrelevant materials

b) Student separates opinions from facts

c) Student identifies need to collect data

2) Identify and State Accounting Issues (Critical Thinking-reason \& understanding Conceptual Material)

a) Student understands the transaction or events

b) Student recognizes items not stated: unperformed duties, hidden contingencies

c) Student classifies the issue into a broad category: revenue recognition, matching, etc.

3) Research the Relevant Authoritative Literature (Research \& Critical thinking -reasoning)

a) Student researches GAAP and doesn't discuss tax requirements

b) Student researches the issue identified in item 2

c) Student seems to understand the standards researched

4) Interpret and Apply the Accounting Literature to the Issue(s) (Critical Thinking-understands multiple perspectives \& applies conceptual understanding)

a) Identify and state the solution: States a clear solution that a client can understand; or

b) Identifies alternative ways to treat if appropriate.

c) Defends solution and /or plausible alternatives clearly with judgment that is based on accounting literature/concepts. (Analyzes deeply enough that each portion of the research is tested, e.g. if extraordinary event needs to be material, unusual, and infrequent, student tests items against all three.)

d) Uses material (facts) from case and compares to the accounting literature

e) Develops necessary supporting schedules, recommends correct journal entry as appropriate.

f) Organizes thoughts in a logical order demonstrating deductive or inductive reasoning. 
NOTES 